Running Head: IMPACT OF THE PLATEWARE ON THE PERCEPTION OF FOOD

Resubmitted to: Journal of Sensory Studies (May, 2018)

Influence of the color and size of the plate on the subjective ratings of, taste expectations concerning, and willingness-to-pay for, Asian noodles

Hui Zhao ${ }^{1}$, Jun $\mathrm{An}^{1}$, Charles Spence ${ }^{2}$, \& Xiaoang $\mathrm{Wan}^{1}$

1. Tsinghua University

2. Crossmodal Research Laboratory, Department of Experimental Psychology, University of Oxford, UK

Correspondence: Xiaoang Wan, Department of Psychology, School of Social Sciences, Tsinghua University, Beijing, China 100084.

Electronic mail: wanxa@mail.tsinghua.edu.cn

This research was supported by the National Natural Science Foundation of China (Grant No. 71472106) awarded to Xiaoang Wan, and Tsinghua University Initiative Scientific Research Program. 


\section{PLATE \& NOODLES}

3 Two experiments were designed to investigate the effect of plate color and plate size

4 on taste expectations, subjective ratings of, and willingness-to-pay for, Asian noodles

5 and Italian pastas. Chinese participants viewed photographs of these foods served on

6 plates of different colors and sizes, rated their liking, familiarity, taste expectations for

7 the foods, and indicated how much they would be willing to pay for them. The foods

8 were presented against the backdrop of store-bought or computer-edited colored

9 plates. Presenting the food on white plates resulted in the highest familiarity scores.

10 Interestingly, the participants were willing to pay approximately $16 \%$ more for the

11 same quantity of Asian noodles when served on smaller (rather than larger) plates.

12 Different patterns of results were observed with two types of Italian pasta that the

13 Chinese participants were less familiar with, suggesting a moderating role of the 14 familiarity people have with the foods.

15

17 The present study provides novel findings concerning the influence of plateware on 18 Asian noodles, a commonly-eaten food in many Asian countries. The findings suggest

19 a fundamental difference between the role of plateware in the subjective ratings of, 20 and taste expectations concerning, regularly consumed familiar and unfamiliar foods

21 as in the present study and the snack food in previous studies. These findings are therefore relevant to those researchers and practitioners interested in how receptacle,

23 as an important contextual factor, influences consumers' perception and consumption 


\section{PLATE \& NOODLES}

24 of foods. These findings also have direct implications for those serving food in 25 restaurants.

26 Keywords: Plateware; Color; Noodles; Plate size 27 


\section{PLATE \& NOODLES}

\section{INTRODUCTION}

Many studies have revealed that our consumption of food is influenced not only by its color (Piqueras-Fiszman and Spence 2014), but also by the color of various product-extrinsic stimuli, such as the container used to serve the food, the color of any packaging, or even the color of the ambient lighting. Even though Singh (2006) suggested that the color red stimulates the appetite, red plates have actually been shown to reduce the intake of unhealthy (e.g., snack) foods such as popcorn, chocolate chip, pretzels, and white bread (Bruno et al. 2013; Genschow et al. 2012; Reutner et al. 2015; see Spence, 2018, for a review).

Similarly, people's subjective ratings of the flavor of food are also influenced by the physical and sensory properties of the plateware/crockery used to serve the food, such as their color. For example, the same salty/sweet popcorn served in a blue bowl was rated as slightly, but significantly sweeter/saltier than those served on a white bowl, respectively (Harrar et al. 2011). Meanwhile, both strawberry mousse and a slice of cheesecake served on a white plate were rated as sweeter than when presented on a black plate instead (Piqueras-Fiszman et al. 2012; Stewart and Goss 2013). Elsewhere, it has been shown that people expect bean curd that is served on a red plate to be spicier than that served on a white plate (Tu et al. 2016). Intriguingly, such expectancy effects were shown to carry over to the tasting experience.

It might be difficult to draw any straightforward conclusions regarding whether the color of the container enhances consumers' subjective ratings of specific foods, or 
49 whether instead the same result would be expected no matter what food happened to

50 be presented on a plate of a given color. It is also possible that different flavors/tastes

51 of the food might be subject to the influence of the containers/plateware in different

52 ways. As summarized above, most of the foods whose ratings have been shown to be

53 influenced by the receptacles are hedonically-positive, such as cakes and snack foods

54 (i.e., chocolate chip or popcorn). By contrast, it remains unknown as to whether

55 people's perception of those foods that are eaten regularly in daily life (and which

56 constitute a major part of the diet and energy supply), might be influenced by the

57 physical or sensorial properties of the containers in which they happen to be served.

58 Asian noodles constitute one such flour-based food with a huge market in China

59 (Liu 2014). Surprisingly, to date, there has been little psychological research on them.

60 Recently, people's subjective ratings of, and taste/flavor expectations concerning

61 Asian noodles have been shown to be influenced by the materials of the receptacles

62 that are used to present them (Zhou et al. 2015). Specifically, the ceramic receptacles

63 led to sweeter and less savory taste expectations concerning the food than the stainless

64 steel receptacles. Nevertheless, it should be noted when the materiality of the

65 receptacles changed from ceramic to stainless steel, the color of the receptacles also

66 changed from white to silver. Therefore, it remains unclear how people’s expectations

67 concerning the sensory/hedonic qualities of noodles might be influenced by the color

68 of the receptacles in which they happen to be presented. 

present study, and plates in a variety of different colors to present them on. In addition to the color of the plates, the size of the plate was also manipulated in order to examine the interaction between these two physical attributes of the crockery. It

73 should be noted that plate size has a substantial effect on the amount of food that is

74 both served and consumed (for a meta-analysis of 56 studies from 20 articles, see Holden et al. 2016).

Three specific research questions were addressed in two experiments: First, does the color of the plate influence people's taste expectations, subjective ratings of, and willingness-to-pay for, Asian noodles? It seems reasonable to expect the influence of the plate color on people's subjective ratings of Asian noodles; whereas it might be less likely to observe an effect on people's taste expectations, because Asian noodles

81 are commonly consumed as the background food, onto which flavorful sauces are

82 added as foreground flavors. Second, how does the size of the plate interact with its

83 color to influence people's taste expectations, subjective ratings of, and

84 willingness-to-pay for, Asian noodles? It appears plausible to expect the influence of

85 the plate size on people's willingness-to-pay for Asian noodles; whereas neither the

86 color nor the size of the plates might be powerful enough to influence people’s taste

87 expectations concerning typically flavorless food such as Asian noodles. And third,

88 we were also interested in comparing the results obtained with Asian noodles to those 89 seen with Italian pasta, which differ in shapes, textures, and familiarity that Chinese 
participants have with, in terms of how their ratings might be influenced by the color and/or size of the plate used to serve them.

\section{MATERIALS AND METHODS}

\subsection{Experiment 1: Test with store-bought colored plates}

\subsubsection{Participants}

Eighty-two Chinese participants (mean age $=21.5$ years, $\mathrm{SD}=2.2$, ranging from 18 to 27 years; 41 female) were recruited from the subject pool of the Applied Cognition Laboratory of Tsinghua University. All of the participants have normal color vision and normal/corrected-to-normal vision. The experiment was approved by the ethics committee of the Psychology Department of Tsinghua University, and conformed to the ethical standards for conducting research established by the American Psychological Association. Each participant was compensated with 20 Chinese Yuan (CNY, symbolized by $¥)$ for taking part.

\subsubsection{Materials}

All of the participants came to the Applied Cognition Laboratory of Tsinghua University to complete the task via www.qualtrics.com. Photos of Asian noodles (240 pixels wide $\times 180$ pixels high) were presented on 17-inch monitors with a resolution of $1024 \times 768$ pixels, and a refresh rate of $60 \mathrm{~Hz}$. The photos were viewed one at a time at a distance of approximately $50 \mathrm{~cm}$ in a white-lighted room (see Figure 1 for illustrations). The noodles were purchased from one of the dining halls of Tsinghua 
111 University, and presented on the colored plates purchased from the local IKEA store

112 in Beijing (www.ikea.cn). We chose four plate colors which are commonly seen in

113 the local market, including white (H: $67^{\circ}$, S: 4\%, B: $\left.84 \%\right)$, blue (H: $191^{\circ}$, S: $36 \%$, B:

$11476 \%)$, red (H: $15^{\circ}$, S: 70\%, B: 76\%), and beige (H: 60 , S: $33 \%$, B: $\left.76 \%\right)$. These

115 plates also varied in size, half were large (27 cm in diameter) and the remainder were

116 small (21 cm in diameter), both of which are commonly seen dimensions in the local

117 market, and are shown in the left and right columns of Figure 1, respectively. When

118 preparing the photos, approximately $50 \mathrm{~g}$ of Asian noodles were placed on the center

119 of each plate. Photos were taken from exactly the same viewpoint and distance, and a

120 total of eight photos ( 2 plate sizes $\times 4$ plate colors) were used. The whole experiment

121 lasted approximately 10 minutes.

122

123

124

125

126

128

129

\subsubsection{Design and procedure}

In Experiment 1, we used a 4 (Plate Color: white, blue, red, or beige) $\times 2$ (Plate Size: large or small) within-participants experimental design. The 8 photos of Asian noodles served on different plates were presented to the participants in a random order, with one photo shown on each page. When viewing each photo, the participants

131 were asked to rate how familiar and pleasant the noodles looked, as well as how 
132 congruent the noodles were with the plate on which they were presented, all on

133 7-point scales. They were also asked to rate how sweet and how savory they expected

134 the noodles to taste on 7-point scales. The participants also specified how much (in

135 CNY) they would be willing to pay for the noodles (to indicate their

136 willingness-to-pay), with zero CNY suggesting no willingness to pay. Before the

137 experiment ended, all of the participants were also asked about how often they

138 consumed Asian noodles in their daily life (i.e., never, occasionally, sometimes, or

139 often).

140

$141 \quad$ 2.1.4 Data analysis

142 First, we performed 4 (Plate Color: white, blue, red, or beige) $\times 2$ (Plate Size:

143 large or small) repeated-measure Multivariate Analysis of Variance (MANOVA) on

144 the mean subjective rating scores given by all the participants, including the

145 familiarity, pleasantness, and food-plate congruency scores. We then performed

146 subsequent univariate Analyses of Variance (ANOVAs) on each type of scores. Next,

147 we performed the Plate Color $\times$ Plate Size repeated-measures MANOVA and

148 subsequent univariate ANOVAs on the mean scores concerning the expected

149 sweetness/savory taste of the noodles. After that, we performed the Plate Color $\times$

150 Plate Size repeated-measures ANOVA on the willingness-to-pay data. In order to

151 interpret significant interaction terms observed in the ANOVAs mentioned above, we 
152 also performed pairwise comparisons. Note that in all of the reported tests, $p$ values

153 are reported after Bonferroni-correction for multiple comparisons.

154

\subsection{Experiment 2: Test with computer-edited colored plates}

156

157

158

159

160

161

162

163

164

165

166

167

168

169

170 171 via Adobe Photoshop CC software (see Figure 3). It should be noted that we

172 presented green as one of the plate colors in Experiment 2, but not the beige color as

\subsubsection{Participants}

One hundred and eight Chinese participants (mean age $=20.8$ years, SD $=2.1$, ranging from 18 to 27 years; 55 female) were recruited from the same subject pool as in Experiment 1. None of the participants had taken part in Experiment 1.

\subsubsection{Materials}

The materials used in Experiment 2 were similar to those in Experiment 1 with the following exceptions: First, as can be seen in Figure 2, photos of three types of foods, including Asian noodles (as in Experiment 1), and two types of Italian pasta, i.e., Fusilli pasta (Melissa brand, http://www.melissa.gr/), and Penne pasta (Barilla brand, http://www.barilla.it/) were shown to the participants. Second, in order to show exactly the same noodles on each and every plate, we took the photos when the food samples were presented on grey plates (diameter in 20 or $26 \mathrm{~cm}$ ), and then modified the colors of the plates to appear white $\left(\mathrm{H}: 55^{\circ}, \mathrm{S}: 19 \%, \mathrm{~B}: 95 \%\right)$, red $\left(\mathrm{H}: 356^{\circ}, \mathrm{S}\right.$ : 99\%, B: $81 \%$ ), blue (H: $218^{\circ}$, S: $42 \%$, B: $\left.55 \%\right)$, or green (H: $124^{\circ}$, S: $79 \%$, B: $\left.63 \%\right)$ 
173 in Experiment 1, as we did not observe any significant difference between the beige

174 plate and any of the other plate colors in Experiment 1 (see the Results and

175 Discussions section below for details). Therefore, a total of 24 images (4 plate colors

$176 \times 2$ plate sizes $\times 3$ types of foods) were presented to the participants in Experiment 2 .

177

178

179

180

181

182

183

184

185

186

187

188

189

190

191

192

193

INSERT FIGURES 2 \& 3 ABOUT HERE

\subsubsection{Design and procedure}

In Experiment 2, we used a 4 (Plate Color: white, red, blue, or green) $\times 2$ (Plate Size: large or small) $\times 3$ (Food Type: Asian noodle, Fusilli pasta, or Penne pasta) within-participants experimental design. The procedure of Experiment 2 was similar to that of Experiment 1 except for that Experiment 2 was completed online via www.unipark.de. The whole experiment lasted approximately 30 minutes.

\subsubsection{Data analysis}

First, we performed 4 (Plate Color: white, red, blue, or green) $\times 2$ (Plate Size: large or small) $\times 3$ (Food Type: Asian noodle, Fusilli pasta, or Penne pasta) repeated-measures MANOVA and subsequent univariate ANOVAs on the mean scores of subjective ratings, including the familiarity, pleasantness, and food-plate congruency scores. Next, we also performed the Plate Color $\times$ Plate Size $\times$ Food Type repeated-measures MANOVA and subsequent univariate ANOVAs on the mean 
194

195

scores concerning the expected sweetness/savory taste of the foods. After that, we performed the Plate Color $\times$ Plate Size $\times$ Food Type repeated-measures ANOVA on the willingness-to-pay data. Similar to Experiment 1, we also performed pairwise comparisons with Bonferroni corrections to interpret significant interaction terms observed in the ANOVAs mentioned above.

\section{RESULTS AND DISCUSSIONS}

\subsection{Experiment 1: Test with store-bought colored plates}

\subsubsection{Results}

The influence of plate color and size on subjective ratings of food

Mean rating scores of familiarity, pleasantness, and food-plate congruency in Experiment 1 are shown in Figure 4. The results of 4 (Plate Color: white, blue, red, or beige) $\times 2$ (Plate Size: large or small) repeated-measure MANOVA on familiarity, pleasantness, and food-plate congruency revealed a significant main effect of Plate Color, $\lambda=0.84, F(9,587)=4.77, p<.001, \eta_{p}{ }^{2}=0.06$, and Plate Size, $\lambda=0.57, F(3$, $79)=19.96, p<0.001, \eta_{p}{ }^{2}=.43$, but no significant interaction term, $\lambda=0.97, F$ (9, 587) $=0.87, p=0.56$. Subsequent univariate ANOVAs revealed a significant main effect of Plate Color on all three scores, all Fs $>3.30$, ps $<0.021$. Post-hoc pairwise comparisons revealed that the participants rated the noodles served on the white plate as looking the most familiar, all $t s>2.79$, ps $<0.039$; whereas the blue plate (3.2) was considered less congruent with the noodles than either the red (3.8) or white (4.1) plates, both $t \mathrm{~s}>3.10$, ps $<0.016$. None of other pairwise comparisons reached significance on any of the scores, all $t \mathrm{~s}<2.68$, $p \mathrm{~s}>0.05$. The ANOVAs also revealed 
217 a significant main effect of Plate Size on all three scores, all $F$ s $>39.01$, $p$ s $<0.001$,

$218 \eta_{p}{ }^{2}>0.32$. These results therefore suggest that the Asian noodles served on the small

219 plates were rated as more familiar (4.6 vs. 4.1), more pleasant (4.0 vs. 3.3), and more

220 congruent with the container (4.1 vs. 3.3) than those served on the large plates. There

221 was no interaction between Plate Color and Plate Size, all Fs $<1.17$, ps $>0.32$.

222

223

224

225

226

228

INSERT FIGURE 4 ABOUT HERE

The influence of plate color and size on taste expectations

Mean scores concerning the expected sweetness/savory taste of the noodles are shown in Figure 5. The results of Plate Color $\times$ Plate Size repeated-measures MANOVA on these scores did not reveal any significant main effects or an interaction, all $\lambda \mathrm{s}<0.99, \mathrm{Fs}<2.50$, ps $>0.09$. What is more, subsequent univariate ANOVAs failed to reveal any significant main or interaction effects either, all Fs < $3.26, p s>0.07$.

INSERT FIGURE 5 ABOUT HERE

237

The influence of plate color and size on the willingness-to-pay for food 
239 were excluded from the data analyses because their willingness-to-pay scores were

240 beyond two standard deviations from the group mean. The means of the remaining

241 data are also displayed in Figure 5. The results of a Plate Color $\times$ Plate Size 242 repeated-measures ANOVA revealed a significant main effect of Plate Color, $F(3$, $243234)=4.45, p<0.01, \eta_{p}^{2}=0.05$. Post-hoc pairwise comparisons revealed that the 244 participants were not willing to pay as much for the noodles when served on the blue 245 plates ( $¥ 4.2$ ) as compared to when they were served on the red (¥ 4.9) or white (¥ 5.0) 246 plates instead, both $t$ s $>3.08$, ps $<0.02$. None of other pairwise comparisons reached 247 significance, all $t \mathrm{~s}<1.84$, $p$ s $>0.42$. The results also revealed a significant main 248 effect of Plate Size, $F(1,78)=23.79, p<0.001, \eta_{p}{ }^{2}=0.23$, whereas the Plate Color $\times$ 249 Plate Size interaction effect was, once again, not significant, $F(3,234)<1$. These 250 results suggest that the participants were willing to pay significantly more for the 251 same quantity of noodles when they were served on small plates ( $¥ 5.0$ ) than when 252 they were served on large plates (¥ 4.3).

253 Last, but by no means least, all of the participants reported that they had eaten 254 Asian noodles, and they occasionally (25.6\%), sometimes (43.9\%), and often (30.5\%) 255 ate Asian noodles in daily life. 
259 plate to be less congruent with the noodles and were willing to pay less, as compared 260 to when the same noodles were served on the red or white plates instead. The results 261 obtained with Asian noodles are consistent with previous findings showing that 262 consumers are willing to pay more for a glass of an alcoholic drink when the 263 receptacle to serve it was considered to be congruent than when it was incongruent 264 (Wan et al. 2015). Another result to emerge from the present study was that serving 265 the noodles on the small plates resulted in their receiving higher familiarity, 266 pleasantness, and congruency scores than those served on the large plates. What is 267 more, the participants were willing to pay significantly (approximately 16\%) more for 268 the same quantity of noodles when they were served on the small plates than on the 269 large plates instead, presumably because small plates might lead the participants to 270 overestimate the amount of food (when compared to large plates) due to the 271 well-known Delboeuf illusion (e.g., McClain et al. 2014).

272 On the other hand, neither the color nor the size of the plates influenced 273 participants' expectations concerning the taste of the noodles. The absence of such an 274 effect might result from the participants' everyday experience with Asian noodles, 275 considering that all of the participants in the present study have (occasionally, 276 sometimes, or often) eaten such food in their daily life. That is, Asian noodles are 277 typically relatively tasteless and are often eaten only after being mixed with some 278 kind of flavorful accompaniment (e.g., sauce). Note that the noodles presented in 
279 Experiment 1 were shown by themselves without being adulterated by any sauces.

280 Consequently, the color or size of the plate did not influence the expectations 281 concerning the taste of the noodles. It is possible that the background plate color 282 might accentuate the expected taste of a familiar food that already has a taste/flavor, 283 such as the spicy bean curd in Tu et al.'s (2016) recent study, but cannot create an 284 expectation of taste in a very bland food product.

285 In Experiment 2, we attempted to replicate these results, while also assessing the 286 impact of plate size/color on another kind of food that were likely to be less familiar 287 to our participants (specifically, we showed pictures of different types of Italian pasta) 288 in order to determine whether familiarity with the food also mattered. Specifically, we 289 chose two types of Italian pasta that are available in local supermarkets or restaurants 290 to our participants, Fusilli and Penne pasta. They differ in both shape and texture from 291 Asian noodles.

\subsection{Experiment 2: Test with computer-edited colored plates}

$294 \quad 3.2 .1$ Results

The influence of plate color and size on subjective ratings of food

Mean familiarity, pleasantness, and food-plate congruency rating scores are

297 shown in Figure 6. The 4 (Plate Color: white, red, blue, or green) $\times 2$ (Plate Size:

298 large or small) $\times 3$ (Food Type: Asian noodle, Fusilli pasta, or Penne pasta) 
300 Color, and Food Type, all $\lambda>0.66$, Fs $>15.09$, $p s<0.001, \eta_{p}{ }^{2}>0.12$. The results also 301 revealed a significant two-way interaction between Plate Size and Food Type, $\lambda=$ $3020.90, F(6,424)=3.87, p<0.001, \eta_{p}{ }^{2}=0.052$, and between Plate Color and Food 303 Type, $\lambda=0.94, F(18,1811)=2.23, p=0.002, \eta_{p}{ }^{2}=0.020$. Neither of the other 304 interaction effects was significant, both $F \mathrm{~s}<1.44$, ps $>0.16$.

305

INSERT FIGURE 6 ABOUT HERE

Subsequent univariate ANOVAs revealed significant main effects of Plate Color on all three ratings, all $F \mathrm{~s}>10.46$, $p \mathrm{~s}<0.001, \eta_{p}{ }^{2}>0.09$, though the main effect on congruency ratings was qualified by a significant interaction between Plate Color and Food Type, $F(6,642)=2.91, p<0.01, \eta_{p}{ }^{2}=0.026$, whereas the interaction terms between Plate Color and Food Type were not significant, both Fs $<1.89$, ps $>0.08$. As for familiarity and pleasantness scores, post-hoc pairwise comparisons revealed that the foods presented on the white plates were considered to be the most familiar, all $t$ s $>3.92$, ps $<0.001$, and were rated as looking more pleasant than those served on the red or green plates, both $t \mathrm{~s}>3.76$, ps $<0.002$. As for the food-plate congruency scores (see Table 1 for statistics), Asian noodles and Penne pasta were considered most congruent with white plates as compared to any of the other three colors; and they were rated as more congruent with blue plates than with the red or green plates as well. Fusilli pasta was considered more congruent with white plates than with red 
321 or green plates, while it was also judged more congruent with the blue plates than

322 with the red plates. Neither of the other pairwise comparisons reached significance.

323

324

326

327

328

330

331

332

333

335

336

339

340 8

INSERT TABLE 1 ABOUT HERE

The ANOVAs also revealed significant main effects of Plate Size on all three rating scores, all $F \mathrm{~s}>23.74, p \mathrm{~s}<0.001, \eta_{p}{ }^{2}>0.18$. These results therefore suggest that the foods served on the small plates were rated as more familiar (4.2 vs. 3.9), more pleasant (3.6 vs. 3.3), and, what is more, gave rise to higher food-plate congruency scores (3.5 vs. 3.2) than those foods served on the large plates. That being said, these main effects were qualified by the Plate Size and Food Type interaction terms, all Fs $>3.83, p s<0.05, \eta_{p}{ }^{2}>0.03$. As summarized in Table 2, pairwise comparisons revealed that both Asian noodles and Fusilli pasta were rated as being more familiar, pleasant, and congruent with the small plates than with the large ones; whereas no such patterns were observed with Penne pasta.

INSERT TABLE 2 ABOUT HERE

341 on familiarity scores, $F(2,214)=46.2, p<0.001, \eta_{p}^{2}=0.30$. Unsurprisingly, 
342 post-hoc comparisons revealed that the Chinese participants tested in the present

343 study rated themselves as more familiar with Asian noodles than with the two types of

344 Italian pastas, both $t$ s $>7.72$, ps $<0.001$, whereas Fusilli pasta and Penne pasta

345 received comparable familiarity scores, $t(107)=1.30, p=0.59$. None of the other

346 main or interaction effects were significant, all $F \mathrm{~s}<2.56$, $p \mathrm{~s}>0.05$.

348 The influence of plate color and size on taste expectations

349 Mean scores concerning the expected sweet and savory taste of the food are 350 shown in Figure 7. The Plate Size $\times$ Plate Color $\times$ Food Type repeated-measures 351 MANOVA revealed a significant main effect of Plate Size, $\lambda=0.93, F(2,106)=3.98$, $352 p=.022, \eta_{p}{ }^{2}=0.070$, of Plate Color, $\lambda=0.95, F(6,640)=2.77, p=0.012, \eta_{p}{ }^{2}=0.025$, 353 and of Food Type, $\lambda=0.88, F(4,426)=7.07, p<0.001, \eta_{p}{ }^{2}=0.062$. None of the 354 interaction terms was significant, all $F \mathrm{~s}<1.44$, ps $>0.22$.

355

356 357 358 359 360

\section{INSERT FIGURE 7 ABOUT HERE}

Subsequent univariate ANOVAs revealed a significant main effect of Plate Color on savory scores, $F(3,321)=4.13, p<0.01, \eta_{p}{ }^{2}=0.04$. Post-hoc pairwise comparisons revealed that the foods presented on the white plates were expected to be more savory than those served on the red or green plates, both $t \mathrm{~s}>2.80$, ps $<0.036$, whereas none of other pairwise comparisons reached significance, all $t \mathrm{~s}<1.94$, $p$ s $>$ 
363

364

365

366

367

368

369

370

371

372

373

374

375

380

0.33. The results also revealed a significant main effect of Plate Size on the savory scores, $F(1,107)=7.40, p<0.01, \eta_{p}^{2}=0.07$, thus suggesting that the food presented on the smaller plates was expected to be slightly more savory (3.4 vs. 3.3) than when served on the larger plates instead. What is more, the results also revealed significant main effects of Food Type on sweet and savory ratings, both $F \mathrm{~s}>11.10$, $p$ s $<0.001$, $\eta_{p}{ }^{2}>0.09$, whereas none of the interaction terms were significant, all $F \mathrm{~s}<2.68$, $p \mathrm{~s}>$ 0.07. Post-hoc pairwise comparisons revealed that participants expected the Penne pasta to be both sweeter and less savory, than the Fusilli pasta or the Asian noodles, all ts $>3.43$, ps $<0.01$, whereas none of other pairwise comparisons reached statistical significance, both $t \mathrm{~s}<1.22$, ps $>0.68$.

\section{The influence of plate color and size on the willingness-to-pay for food}

Preliminary analysis of the willingness-to-pay data revealed that the results from six of the participants had to be excluded from the following data analyses because they reported prices that were more than two standard deviations from the group mean.

The means of the data from the remaining participants are shown in Figure 7. The results of the Plate Color $\times$ Plate Size $\times$ Food Type repeated-measures ANOVA revealed significant main effects of Plate Color and Plate Size, both Fs $>8.38$, ps < $0.001, \eta_{p}{ }^{2}>0.07$, but they were qualified by significant interactions between Plate Color and Plate Size, $F(3,303)=2.71, p<0.05, \eta_{p}{ }^{2}=0.026$, and between Plate Size and Food Type, $F(2,202)=7.80, p<0.001, \eta_{p}{ }^{2}=0.07$. Post-hoc pairwise 


\section{PLATE \& NOODLES}

384

comparisons revealed that the participants were willing to pay significantly more for exactly the same food when served on the smaller plates than when served on the larger plates when they were red, blue, or green, all $t \mathrm{~s}>3.45$, $p$ s $<0.001$, whereas the similar trend for white plates failed to reach statistical significance, $t(101)=0.56, p=$ 0.58. On the other hand, the participants in Experiment 2 were willing to pay significantly more for the food served on the small rather than on the large plates, $t$ $(101)=5.43, p<0.001$, Cohen's $d=0.54$, for Fusilli pasta, and $t(101)=5.35, p<$ 0.001, Cohen's $d=0.53$, for Asian noodles, but no such pattern was seen for the Penne pasta, $t(101)=0.24, p=0.81$.

Last, but by no means least, the percentages of the participants who reported that they never, occasionally, sometimes, and often ate each type of food in daily life was as follows: Asian noodles, 0\%, 13\%, 39\%, and 48\%, respectively; Fusilli pasta, 44\%, 48\%, 8\%, and 0\%, respectively; and Penne pasta, 28\%, 60\%, 10\%, and $2 \%$, respectively.

\subsubsection{Discussion}

The results of Experiment 2 replicated the general pattern of results found in Experiment 1. That is, both the color and size of the plates influenced participants' subjective ratings of, and willingness to pay for, Asian noodles. That being said, we obtained some specific results with the computer-edited plate colors in Experiment 2 that were different from those reported with store-bought plates observed in 
405 Experiment 1. In particular, the participants considered the computer-edited red or 406 green plates to be less pleasant, less congruent with the food, and were willing to pay 407 less for it compared to the white plate in Experiment 2. By contrast, the store-bought 408 red and white plates were considered to be equally pleasant and congruent with the 409 Asian noodles, and elicited comparable willingness-to-pay in Experiment 1. Taken 410 together, while the influence of plate color on the subjective ratings of, and 411 willingness-to-pay for, foods such as Asian noodles are robust, it might be moderated 412 by the hue of the plate color.

On the other hand, it should also be noted that the type of food (and, in 414 particular, its color; see Lyman 1989) might also moderate the influence of plate color 415 and size on ratings of food. When the participants were not very familiar with the 416 food such as when the Chinese participants in the present study viewed plates with 417 Italian pasta, their subjective ratings of, willingness to pay for, and even taste 418 expectations concerning, the food were more easily influenced by the physical 419 properties of the containers to serve the food, such as their color and size.

\section{GENERAL DISCUSSION}

The results of two experiments reported here revealed the influence of the color

423 and size of the plate used to present foods, on the subjective ratings of, and 424 willingness to pay for these foods. That is, food served on white plates was 
426 plates are much more commonly used to serve food in daily life than other colors, 427 such as red, beige, green, or blue as used in the present study. According to estimates, 428 half of all plates that are sold in Europe are white (Hultén et al. 2009). As for the plate 429 size, Asian noodles served on small plates received higher familiarity, pleasantness, 430 food-plate congruency, and willingness-to-pay scores in both experiments, 431 presumably because small plates might lead the participants to overestimate the 432 amount of food as compared to larger plates. Such results have been attributed to the 433 Delboeuf illusion whereby the perception of a portion of food is influenced by the 434 size of the circle (e.g., in this case, the plate) that surrounds it (e.g., McClain et al. 435 2014).

On the other hand, we obtained somewhat different results between the two 437 experiments, involving store-bought and computer-edited red and blue plates 438 (Experiments 1 and 2, respectively). That is, the store-bought red plate received 439 comparable rating (except for familiarity) and willingness-to-pay scores as the white 440 plate, whereas the computer-edited red plate received lower ratings than the white 441 plate. By contrast, the store-bought blue plate was considered less congruent with 442 Asian noodles than the store-bought red plate, whereas the computer-edited blue plate 443 was considered as more congruent with Asian noodles than the computer-edited red 444 plate. Here it should be noted that the store-bought red and blue plates were reflective, 445 whereas the computer-edited red and blue ones were not reflective (i.e., they were 446 matte) without any shadows, and they differed in hue. Taken together, these findings 


\section{PLATE \& NOODLES}

447 448 449 451 452 453 454 455 456 457 458 460 461 462 463

464 the food flavor/taste (see Lyman 1989, on this point; though see also Bruno et al. 465 2013). Using colored tableware that provides the maximal visual contrast to the food 466 might be helpful for special populations such as Alzheimer’s disease patients in terms 467 of enhancing their intake of food and/or drinks (Dunne et al. 2004; Spence 2017).

suggested that the hues and reflectivity of the colors of the plate might moderate its influence on the subjective ratings of, and willingness-to-pay for foods such as Asian noodles.

It should be noted that the color red (when not associated with a brand, or any other meaning) has been shown to reduce the intake of those foods that are considered unhealthy (Bruno et al. 2013; Genschow et al. 2012; Reutner et al. 2015); and it has been suggested that serving food from blue trays may reduce consumers' food intake compared to trays of other colors (at least in Depression-era North America, Crumpacker 2006). Note, also, how blue foods are rare in nature, so people might have worries about the safety of blue food (Suzuki et al. 2017) and prefer them less (Lee et al. 2013). Therefore, one should perhaps be cautious about using red or blue as plateware colors for general populations (see Spence, submitted, for a review).

It is, of course, possible that the color of the plate might change the appearance properties of the food itself (Lampi 1973; though see Schifferstein et al. 2017). Alternatively, however, it is also possible that the contrast (i.e., the perceived color difference) between the foods and the receptacles, rather than the color of the receptacles themselves, is what determines people's expectations and perception of 
468 469 470 471 482

What is more, the world-famous Barilla pasta brand uses dark blue as its packaging color, presumably to make their pasta stand out against the packaging (see Figure 8 for an illustration).

\section{INSERT FIGURE 8 ABOUT HERE}

It is also worth noting that food can provide a certain degree of textural complexity and visual arrangement cues (e.g., artistic plating), which might influence participants' perception and expectation of the food (Michel et al. 2014, 2015; Okajima and Spence 2011; Zellner et al. 2010, 2011). The results of the present study suggest that the type of food might also moderate the influence of plate color and size on people’s expectations. Unsurprisingly, the Chinese participants who took part in the present study were not as familiar with the Italian pastas as with Asian noodles.

While consumer's frequency of consumption of the pastas might influence their expectations and liking of these foods (Laureati et al. 2016), 44\% and 28\% of our Chinese participants reported never having eaten Fusilli and Penne pasta, respectively. That being the case, their subjective ratings of, willingness-to-pay for, and even taste expectations concerning, the pastas, were nevertheless still influenced by the color and size of the containers used to serve the food. Taken together, these findings suggest that plate color might accentuate the expected taste that a familiar food already originally (and even weakly) has (Harrar et al. 2011; Piqueras-Fiszman et al. 
489 490 491 492 494 495 496 497 498

2012; Tu et al. 2016), as well as that of the unfamiliar food (such as the Italian pastas shown to the participants in the present study), but can hardly create a taste in a tasteless food, such as the Asian noodles which are bland by themselves and are often eaten with sauces of various flavors.

That being said, it should also be noted that the Asian noodles as well as Italian pasta (another food that is commonly consumed in Europe and North America) presented in this study were shown in their natural, and possibly "not ready-to-eat" appearance (i.e., without being combined with any flavorful sauces). Future research will therefore be needed in order to examine these foods in "ready-to-eat" looks with sauces, soup, or even side dishes.

Previous research has shown some cross-cultural differences in the sensory expectations concerning solid foods. For example, Peng and colleagues (2017) recently reported that manipulating the size of the plate (i.e., creating larger vs. smaller portion illusions) has no effect on the expected fullness or the estimated intake of Chinese and Koreans consumers, as compared to significant effects in those participants from Canada and New Zealand. Therefore, future studies will also be needed in order to examine any cross-cultural difference in the influence of receptacles on the perception of food. It will also be interesting to examine whether Asian participants are equally susceptible to the Delboeuf illusion compared to Western participants, considering that Western and Eastern participants exhibit different patterns of results in those cognitive tasks designed to examine the influence 
510 of perceived object-to-object relationship, such as the rod-and-frame task (Ji et al. $5112000)$.

512 In conclusion, the present study provides a number of novel findings concerning

513 the influence of plateware in the case of a commonly-eaten food in many Asian 514 countries, specifically, Asian noodles. It has been estimated that flour-based foods has 515 huge market (c. 600 billion CNY; approximately 89 billion USD every year) in China, 516 while noodles account for $35 \%$ of the yearly flour-based food consumption 517 nationwide (Liu 2014). Our findings suggest a fundamental difference between the 518 role of plateware in the subjective ratings of, and taste expectations concerning snack 519 food consumed for hedonic values in previous studies (Bruno et al. 2013; Genschow 520 et al. 2012; Reutner et al. 2015) and regularly consumed familiar and unfamiliar food 521 as in the present study, suggesting that consumers might react to the visual cues in an 522 adaptive way (see also Reutner et al. 2015). These findings have direct implications in 523 the business of food serving in restaurants. 


\section{PLATE \& NOODLES}

524

525

526

527

528

529

530

531

532

533

534

535

536

537

538

539

540

541

542

543

544

\section{References}

BRUNO, N., MARTANI, M., CORSINI, C. and OLEARI, C. 2013. The effect of the color red on consuming food does not depend on achromatic (Michelson) contrast and extends to rubbing cream on the skin. Appetite, 71, 307-313

CRUMPACKER, B. 2006. The Sex Life of Food: When Body and Soul Meet to Eat. Thomas Dunne Books, New York, NY

DUNNE, T. E., NEARGARDER, S. A., CIPOLLONI, P. B. and CRONIN-GOLOMB, A. 2004. Visual contrast enhances food and liquid intake in advanced Alzheimer’s disease. Clin. Nutr. 23, 533-538

GENSCHOW, O., REUTNER, L. and WANKE, M. 2012. The color red reduces snack food and soft drink intake. Appetite, 58, 699-702

HARRAR, V., PIQUERAS-FISZMAN, B. and SPENCE, C. 2011. There's more to taste in a coloured bowl. Perception, 40, 880-882

HOLDEN, S. S., ZLATEVSKA, N. and DUBELAAR, C. 2016. Whether smaller plates reduce consumption depends on who's serving and who's looking: A meta-analysis. J. Assoc. Consum. Res. 1, 134-146

HULTÉN, B., BROWEUS, N. and VAN DIJK, M. 2009. Sensory Marketing. Palgrave Macmillan, Basingstoke, UK

JI, L. J., PENG, K. and NISBETT, R. E. 2000. Culture, control, and perception of relationships in the environment. J. Pers. Soc. Psychol. 78, 943-955

LAMPI E. 1973. Hotel and restaurant lighting. Cornell Hotel Rest. Assoc. 13, 58-64 
545 LAUREATI, M., CONTE, A., PADAlinO, L., DEL NOBILE, M. A. and 546 PAGLIARINI, E. 2016. Effect of fiber information on consumer's expectation 547 and liking of wheat bran enriched pasta. J. Sensory Stud. 31(4), 348-359

548 LEE, S., LEE, K., LEE, S. and SONG, J. 2013. Origin of human colour preference for 549 food. J. Food Eng. 119, 508-515

550 LIU, X. 2014. Flour-based staple food consumption situation and trend analysis. Agr. 551 Eng. Tec.- Agr. Prod. Proc. Ind. 2014(7), 20-22. [in Chinese]

552 LYMAN, B. 1989. A Psychology of Food, More than a Matter of Taste. Avi, van 553 Nostrand Reinhold, New York, NY

554 MCCLAIN, A. D., VAN DEN BOS, W., MATHESON, D., DESAI, M., MCCLURE, 555 S. M. and ROBINSON, T. N. 2014. Visual illusions and plate design: The effects 556 of plate rim widths and rim coloring on perceived food portion size. Int. J. $557 \quad$ Obesity 38, 657-662

558 MICHEL, C., VELASCO, C., GATTI, E. and SPENCE, C. 2014. A taste of Kandinsky: 559 Assessing the influence of the artistic visual presentation of food on the dining 560 experience. Flavour, 3(1): 7, DOI:10.1186/2044-7248-3-7

561 MICHEL, C., WOODS, A. T., NEUHÄEUSER, M., LANDGRAF, A. and SPENCE, 562 C. 2015. Rotating plates: Online study demonstrates the importance of orientation 563 in the plating of food. Food Qual. Prefer. 44, 194-202 
564 PENG, M., ADAM, S., HAUTUS, M. J., SHIN, M., DUIZER, L. M. and YAN, H. 565 2017. See food diet? Cultural differences in estimating fullness and intake as a 566 function of plate size. Appetite, 117, 197-202

567 PIQUERAS-FISZMAN, B., ALCAIDE, J., ROURA, E. and SPENCE, C. 2012. Is it 568 the plate or is it the food? Assessing the influence of the color (black or white) and 569 shape of the plate on the perception of the food placed on it. Food Qual. Prefer. 24, 570 205-208

PIQUERAS-FISZMAN, B. and SPENCE, C. 2014. Colour, pleasantness, and consumption behaviour within a meal. Appetite, 75, 165-172

573

REUTNER, L., GENSCHOW, O. and WÄNKE, M. 2015. The adaptive eater: Perceived healthiness moderates the effect of the color red on consumption. Food Qual. Prefer. 44, 172-178

SCHIFFERSTEIN, H. N. J., HOWELL, B. F. and PONT, S. C. 2017. Colored backgrounds affect the attractiveness of fresh produce, but not it's perceived color. Food Qual. Prefer., 56, Part A, 173-180

SINGH, S. 2006. Impact of color on marketing. Management Decision, 44, 783-789.

SPENCE, C. 2017. Hospital food. Flavour, 6: 3.

SPENCE, C. 2018. Background colour \& its impact on food perception \& behaviour. Food Qual. Prefer., 68, 156-166.

SPENCE, C. submitted. What is so unappealing about blue food and drink? Int. J. Gastron. Food Sci. 


\section{PLATE \& NOODLES}

585

586

587

588

589

590

591

592

593

594

595

596

597

598

599

600

601

602

603

STEWART, P. C. and GOSS, E. 2013. Plate shape and colour interact to influence taste and quality judgments. Flavour, 2(1): 27, DOI: 10.1186/2044-7248-2-27

SUZUKI, M., KIMURA, R., KIDO, Y., INOUE, T., MORITANI, T. and NAGAI, N. 2017. Color of hot soup modulates postprandial satiety, thermal sensation, and body temperature in young women. Appetite, 114, 209-216

TU, Y., YANG, Z. and MA, C. 2016. The taste of plate: How the spiciness of food is affected by the color of the plate used to serve it. J. Sensory Stud. 31, 50-60

WAN, X., ZHOU, X., WOODS, A. T. and SPENCE 2015. Influence of the glassware on the perception of alcoholic drinks. Food Qual. Prefer. 44, 101-110

ZELLNER, D. A., LANKFORD, M., AMBROSE, L. and LOCHER, P. 2010. Art on the plate: Effect of balance and color on attractiveness of, willingness to try and liking for food. Food Qual. Prefer. 21, 575-578

ZELLNER, D. A., SIEMERS, E., TERAN, V., CONROY, R., LANKFORD, M., AGRAFIOTIS, A., et al. 2011. Neatness counts. How plating affects liking for the taste of food. Appetite, 57, 642-648

ZHOU, X., WAN, X., MU, B., DU, D. and SPENCE, C. 2015. Crossmodal associations and subjective ratings of Asian noodles and the impact of the receptacle. Food Qual. Prefer. 41, 141-150 
605 Table 1. Pairwise comparisons between food-plate congruency scores (on 7-point 606 scales) for different types of food presented on plates in different colors $(N=108)$.

607

\begin{tabular}{|c|c|c|c|c|c|}
\hline & Plate $\mathrm{c}$ & lor & Blue & Green & Red \\
\hline \multirow{6}{*}{ Asian noodles } & White & $t$ & $3.10 *$ & $7.66 * *$ & $6.44 * *$ \\
\hline & & Cohen's d & 0.30 & 0.74 & 0.62 \\
\hline & Blue & $t$ & - & $5.48 * *$ & $4.33^{* *}$ \\
\hline & & Cohen's d & - & 0.53 & 0.42 \\
\hline & Green & $t$ & - & - & 0.98 \\
\hline & & Cohen's d & - & - & - \\
\hline \multirow{6}{*}{ Fusilli pasta } & White & $t$ & 2.61 & $4.64 * *$ & $5.07 * *$ \\
\hline & & Cohen's d & - & 0.45 & 0.49 \\
\hline & Blue & $t$ & - & 2.49 & $2.94 *$ \\
\hline & & Cohen's d & - & - & 0.28 \\
\hline & Green & $t$ & - & - & 0.85 \\
\hline & & Cohen's d & - & - & - \\
\hline \multirow{6}{*}{ Penne pasta } & White & $t$ & $2.88 *$ & $6.26 * *$ & $6.29 * *$ \\
\hline & & Cohen's d & 0.28 & 0.60 & 0.61 \\
\hline & Blue & $t$ & - & $3.80 * *$ & $4.16^{* *}$ \\
\hline & & Cohen's d & - & 0.37 & 0.40 \\
\hline & Green & $t$ & - & - & 0.56 \\
\hline & & Cohen's d & - & - & - \\
\hline
\end{tabular}

608 Note: * denote $p<0.05$, ** denotes $p<0.01$, and all the $\mathrm{p}$ values are reported after 609 Bonferroni-correction for multiple comparisons.

610 


\section{PLATE \& NOODLES}

611 Table 2. Pairwise comparisons of familiarity, pleasantness, and food-plate 612 congruency scores (on 7-point scales) for different types of food presented on plates 613 in different sizes $(N=108)$.

614

\begin{tabular}{llccc}
\hline \multicolumn{2}{c}{ Large vs. small plates } & Asian noodles & Fusilli pasta & Penne pasta \\
\hline Familiarity & $t$ & $4.48^{* *}$ & $4.55^{* *}$ & 0.00 \\
scores & Cohen's $d$ & 0.44 & 0.44 & -
\end{tabular}

$\begin{array}{llllc}\text { Pleasantness } & t & 4.68^{* *} & 4.22^{* *} & 1.52 \\ \text { scores } & \text { Cohen's } d & 0.45 & 0.41 & -\end{array}$

\begin{tabular}{llllc} 
Congruency & $t$ & $5.96^{* *}$ & $5.22^{* *}$ & 0.89 \\
scores & Cohen's $d$ & 0.57 & 0.50 & - \\
\hline
\end{tabular}

615 Note: * denote $p<0.05$, ** denotes $p<0.01$, and all the $\mathrm{p}$ values are reported after 616 Bonferroni-correction for multiple comparisons. 